\title{
Minimally invasive devices for treating lower urinary tract symptoms in benign prostate hyperplasia: technology update
}

This article was published in the following Dove Press journal:

Research and Reports in Urology

19 August 2015

Number of times this article has been viewed

\author{
Fouad Aoun' \\ Quentin Marcelis ${ }^{1,2}$ \\ Thierry Roumeguère ${ }^{2}$ \\ 'Department of Urology, Jules Bordet \\ Institute, ${ }^{2}$ Department of Urology, \\ Erasme Hospital, University Clinics \\ of Brussels, Université Libre de \\ Bruxelles, Brussels, Belgium
}

\begin{abstract}
Benign prostatic hyperplasia $(\mathrm{BPH})$ represents a spectrum of related lower urinary tract symptoms (LUTS). The cost of currently recommended medications and the discontinuation rate due to side effects are significant drawbacks limiting their long-term use in clinical practice. Interventional procedures, considered as the definitive treatment for BPH, carry a significant risk of treatment-related complications in frail patients. These issues have contributed to the emergence of new approaches as alternative options to standard therapies. This paper reviews the recent literature regarding the experimental treatments under investigation and presents the currently available experimental devices and techniques used under local anesthesia for the treatment of LUTS/BPH in the vast majority of cases. Devices for delivery of thermal treatment (microwaves, radiofrequency, high-intensity focused ultrasound, and the Rezum system), mechanical devices (prostatic stent and urethral lift), fractionation of prostatic tissue (histotripsy and aquablation), prostate artery embolization, and intraprostatic drugs are discussed. Evidence for the safety, tolerability, and efficacy of these "minimally invasive procedures" is analyzed.
\end{abstract}

Keywords: lower urinary tract symptoms (LUTS), benign prostatic hyperplasia (BPH), minimally invasive therapies, new approaches, experimental therapy

\section{Introduction}

Benign prostatic hyperplasia (BPH) represents a spectrum of disease, with some patients having more bothersome lower urinary tract symptoms (LUTS) than others. Age, sexual activity, fertility, medical comorbidities, past medical and surgical history, prostate volume, urodynamic parameters, and ultrasound findings are other clinical variables that influence the therapeutic decision-making. Given patients expectations and their willingness to toleratevarious treatment risks and benefits, this range of benign disease necessitates a range of treatment options. Current treatments for $\mathrm{BPH}$ include watchful waiting, lifestyle modifications, phytotherapy, medical therapy, and surgical intervention. Watchful waiting is recommended for mild symptomatic and uncomplicated BPH but carries the risk of progression for a substantial number of patients. ${ }^{1}$ A longitudinal study found that over a 4 -year period, $87 \%$ of men who were mildly symptomatic experienced worsening of their symptoms. ${ }^{2}$ Although well tolerated with mild and infrequent adverse events, there is at present no convincing evidence supporting the use of phytotherapy for BPH. ${ }^{3}$ The currently recommended medications remain first-line therapy for bothersome LUTS. ${ }^{4}$ However, cost and early discontinuation due to side effects are significant drawbacks limiting their longterm use in clinical practice. Conventional interventions considered as the definitive treatment for BPH carry a significant risk of treatment-related complications and even 
death in high-risk patients. ${ }^{5}$ These issues have contributed to the development of "minimally invasive procedures" as an alternative to standard therapies. The concept of a minimally invasive approach to BPH dates back to the 19th century, but early experience with these procedures was disappointing and their use steadily faded over time. However, recent technical advances combined with translational lines of research allowed refinements of pre-existing procedures and modifications of surgical protocols to improve the potential therapeutic value of these new technologies.

This review provides an update on currently available devices and techniques used under local anesthesia for the treatment of BPH/LUTS. The evidence for their safety, tolerability, and efficacy in clinical practice is also analyzed.

\section{Devices for delivery of thermal treatment}

Heat applied to the prostate gland causes tissue necrosis and sloughing, thereby relieving obstruction by decreasing the bulk of the prostate. Several techniques are commonly available, and use different heat sources to induce thermoablation (microwaves, radiofrequency, ultrasound, and water-induced thermotherapy), different route of administration (intraurethral, interstitial, transrectal, and recently transperineal), and different levels of energy (low versus high). Further, different mechanisms of action may be involved (hyperthermia versus thermotherapy). The evolution of devices for delivery of thermal treatment as well as the concept of urethral cooling to avoid harm to non-target tissues had been marked over the past 15 years.

\section{Microwave thermotherapy}

Microwave radiation emitted via an antenna results in marked generation of heat sufficient in magnitude and duration to cause tissue coagulation and necrosis. In 1985, Yerushalmi et al were the first to use microwaves in the treatment of BPH in high-risk surgical candidates. ${ }^{6}$ Early experiences indicated inadequate tissue ablation due to an inappropriate thermal dose, defined as the temperature achieved inside the prostate multiplied by duration of exposure to that temperature. ${ }^{7}$ Since then, advances in microwave treatment systems with respect to antenna design, route of administration, heating patterns, and treatment protocol have allowed delivery of temperatures higher than $45^{\circ} \mathrm{C}$. A higher thermal dose is associated with larger intraprostatic zones of necrosis, a higher peak urinary flow rate $(Q \max )$, and a trend toward improvement of symptoms. ${ }^{8}$ Theses results were confirmed in a prospective randomized clinical study, ${ }^{9}$ and were balanced by the risk of complications and tolerability due to heating of non-target tissue. ${ }^{10}$ The transurethral approach facilitates targeting the prostatic transition zone. ${ }^{10} \mathrm{~A}$ high thermal dose and the transurethral approach led to development of cooling systems to protect the urethra. ${ }^{11}$ Following the same concept, manufacturers have continued to develop higher energy systems, more complex and efficient cooling devices, and more accurate monitoring and targeted devices, leading to third-generation systems. A Cochrane review published in 2012 demonstrated that transurethral microwave thermotherapy provides lasting symptomatic relief (for up to at least 36 months, even in patients with acute urinary retention), increased $Q \max$, and enhanced quality of life for patients with LUTS/BPH. ${ }^{12-15}$ A recent meta-analysis highlights the heterogeneity of the data reported in the literature. ${ }^{16}$ For example, improvement in symptom scores ranges from $0 \%$ to $60 \%$ at 3 months, with an average of $25 \%$. However, the maximal effects of microwave therapy are observed within 3-6 months. ${ }^{13,14}$ Meanwhile, both temporary placement of an intraurethral prostatic bridge catheter and neoadjuvant or adjuvant alpha-blocker treatment were shown to be effective in alleviating symptoms and improving quality of life. ${ }^{17,18}$ The improved energy targeting systems are better tolerated under topical local anesthesia and are associated with fewer sexual complications, such as erectile dysfunction and/or ejaculation disorders. ${ }^{19}$ Potent systemic sedoanalgesic medications were necessary when using the oldest systems. ${ }^{20}$ The relatively limited acceptance of this technology in day-to-day surgical practice is due to its high cost, steep learning curve, and effectiveness and efficacy over time, and durability. Another limitation stems from the limited repeatability of this modality. The uncontrolled back heating effects associated with conventional microwave applicators may result in uncertain and not fully repeatable ablative lesion size and shape. Recently, Bartoletti et al reported promising results for a Phase I clinical study of a new microwave antenna for transperineal thermoablation. This new system AMICAprobe (Hospital Services SpA, Aprilia, Italy), comprises an integrated hydraulic circuit for cooling of the applicator and a miniaturized device (mini-choke) for entrapment of reflected waves. It allows maximum control over radial and longitudinal ablative lesion size and overcomes back heating effects, while keeping the applicator size at a minimum. ${ }^{21}$

\section{Radiofrequency thermotherapy}

Transurethral needle ablation (TUNA) uses radiofrequency energy to cause heating and thereby ablation of prostate tissue. Two antennae placed within the prostate deliver the 
radio waves. Low level radiofrequency generates energy up to $110^{\circ} \mathrm{C}$, leading to coagulation, necrosis, and cell death only in a localized area, because the signal is transmitted into tissue by direct contact. Preservation of the urethra minimizes the short-term complications. The technology for performing TUNA has been available since the early 1990s. The first studies in the USA began in 1994, and the US Food and Drug Administration approved TUNA for the treatment of BPH in $1996 .^{22}$

A meta-analysis published in 2006 assessed the effectiveness of TUNA. ${ }^{23}$ The technique provides lasting symptomatic relief despite high retreatment rates (7.4 times higher than transurethral resection of the prostate [TURP]). ${ }^{24}$ However, symptom and quality of life scores were all higher with TURP, while the complication rates were lower in the TUNA group, with fewer reports of retrograde ejaculation, erectile dysfunction, and strictures. ${ }^{25}$ The technique is well tolerated under local anesthesia. ${ }^{26}$ Another advantage is the recent improvements in electronic technology incorporating thermocouples in the needle to accurately monitor the temperature delivered to the prostate. In addition, in the last decade, the effects of electromagnetic fields on living organisms have been extensively studied. It was demonstrated recently in a canine model that electromagnetic fields can have anti-inflammatory effects and alter the cell proliferation rates and cell membrane permeability. ${ }^{27}$ The first study that investigated the effects of pulsed electromagnetic fields for the treatment of BPH was published in $2011 .{ }^{28}$ Ten patients with BPH were exposed to a pulsed electromagnetic field. The authors reported a statistically significant improvement of symptoms and $Q \max$ as well as a significant reduction in prostate volume and post-void residual compared with ten patients treated with alpha-blockers. The improvement was durable at 1 year of follow-up. The authors concluded that pulsed, short wave duration electromagnetic field at low intensity radiofrequencies seems to exert beneficial nonthermal effects on BPH.

\section{High intensity focused ultrasound}

This technique is based on generation of a focused ultrasound field, which is generated by a piezoelectric transducer coupled into the body and aimed at a target region. The focused waves are absorbed by tissues throughout their propagation and their acoustic energy is converted to heat with a high energy density inside the focal zone. The result is a rapid temperature rise in the target zone to a level exceeding the threshold level of protein denaturation (approxiamtely $60^{\circ} \mathrm{C}$ ), leading to coagulative necrosis. In contrast, there is a low acoustic energy density in the surrounding structures, keeping them spared. This creates elliptical small volume lesions of $50-300 \mathrm{~mm}^{3}$. A larger volume can be ablated without gaps by combining single lesions. High intensity focused ultrasound (HIFU) could there be utilized as a minimally invasive debulking method to treat $\mathrm{BPH}$. The parameters for treating prostate were defined in 1992, and two devices were developed, ie, the Ablatherm ${ }^{\circledR}$ (EDAP TMS, Vaulx-en Velin, France) and the Sonoblate ${ }^{\circledR}$ (Sonacare Medical, LLC, Charlotte, NC, USA); and in 1994, Madersbacher et al published the first clinical study of HIFU for BPH in humans. ${ }^{29}$ Early studies established the safety of this technique and improved our understanding of the biological interaction between focused ultrasound and prostatic tissue. However, the treatment was not effective in terms of $Q \max$ and symptoms. To improve the efficiency, a larger volume of prostate and the bladder neck were included. Also, more power was needed to disintegrate the urethra. The presence of a silicone urinary catheter increased the amount of energy delivered at the urethra. The advent of thermocouples helped to establish the temperature profile throughout the duration of the procedure, and development of a longer focal length probe allowed treatment of a larger prostatic volume, including the anterior fibromuscular stroma. ${ }^{30}$ These technical modifications in association with updated software lead to substantial improvement in symptom scores, $Q \max$, complication rates, and quality of life. ${ }^{31}$ The introduction of circulating cool water kept the rectal temperature lower than body temperature and shortened the treatment time. New developments in monitoring systems allowed more accurate targeting. Magnetic resonance imaging (MRI) and ultrasound elastic fusion allowed accurate definition of the area to be treated. High resolution ultrasound permits live follow-up of HIFU shots and treatment planning that is adjustable in real time. A novel device known as Focal One ${ }^{\circledR}$ (EDAP TMS) was recently commercialized. It combines the latest imaging and treatment technologies of electronic displacement of the focal point associated with contrast-enhanced ultrasound, and is a significant advance in the treatment of BPH and localized prostatic carcinoma. Despite these improvements, the cost of the machine and the procedure as well as the presence of a learning curve has limited its widespread use.

Table 1 summarizes the technical characteristics of the currently available systems. In parallel, a new concept based on focal hyperthermia is emerging. ${ }^{32}$ In contrast with HIFU, which implies high power and high temperatures for a short duration, focal hyperthermia relies on feedback control to maintain a much lower temperature increase $\left(39^{\circ} \mathrm{C}-45^{\circ} \mathrm{C}\right)$ in larger contiguous regions over time frames ranging from 15 to 
Table I Characteristics of HIFU devices in use for the treatment of benign prostatic hyperplasia and localized prostate cancer

\begin{tabular}{|c|c|c|c|}
\hline & Sonablate ${ }^{\circledR} 500$ & Ablatherm $^{\circledR}$ & Focal one $^{\circledR}$ \\
\hline Image & $\begin{array}{l}\text { Single } 6.3 \mathrm{MHz} \\
\text { ultrasound transducer }\end{array}$ & Dual 7.5 MHz ultrasound transducers & $\begin{array}{l}\text { MRI import and fusion with real-time } \\
\text { ultrasound imaging }\end{array}$ \\
\hline Nerve detection & $\begin{array}{l}\text { No data available on preservation } \\
\text { of erectile function with } \\
\text { visualization of } 4.0 \mathrm{MHz} \text { probe }\end{array}$ & $\begin{array}{l}\text { Precise visualization and localization } \\
\text { of neurovascular bundles with } \\
7.5 \mathrm{MHz} \text { probe }\end{array}$ & $\begin{array}{l}\text { Contrast-enhanced ultrasound } \\
\text { increase the image accuracy allowing } \\
\text { improved nerve sparing }\end{array}$ \\
\hline Probe & $\begin{array}{l}\text { Several probe heads needed } \\
\text { which must be manually placed } \\
\text { and manipulated } \\
\text { Operator-dependent }\end{array}$ & $\begin{array}{l}\text { One probe head which is robotically } \\
\text { controlled via extremely precise } \\
\text { software. Accurate delivery of energy } \\
\text { to tolerance of } 0.1 \mathrm{~mm} \\
\text { Fully automated }\end{array}$ & $\begin{array}{l}\text { One probe robotically controlled. } \\
\text { Fully automated }\end{array}$ \\
\hline Precision & $\begin{array}{l}\text { Short focal length requires use } \\
\text { of multiple probes to complete } \\
\text { treatment. Probe geometry poorly } \\
\text { configures to prostate anatomy }\end{array}$ & $\begin{array}{l}\text { Variable lesion size (unitary lesion of } \\
19-26 \mathrm{~mm} \text { height per } 1.7 \mathrm{~mm} \text { width) in } \\
\text { single probe allows energy to be delivered } \\
\text { in pattern conformed to prostate anatomy }\end{array}$ & $\begin{array}{l}\text { Variable lesion size with precise } \\
\text { contour definition of target areas and } \\
\text { unique dynamic focusing technology } \\
\text { Conformational treatment }\end{array}$ \\
\hline Equipment & Two modules, one probe & Two modules, one probe & One module, one probe \\
\hline Safety features & $\begin{array}{l}\text { Constant operator attention to } \\
\text { monitor and adjust device energy } \\
\text { output to prevent injuries to } \\
\text { surrounding tissue }\end{array}$ & $\begin{array}{l}\text { Rectal cooling } \\
\text { Patient movement detection } \\
\text { Real-time rectal wall monitoring }\end{array}$ & $\begin{array}{l}\text { Rectal cooling } \\
\text { Patient movement detection } \\
\text { Real-time rectal wall monitoring }\end{array}$ \\
\hline
\end{tabular}

Abbreviations: HIFU, high intensity focused ultrasound; MRI, magnetic resonance imaging.

60 minutes. Catheter-based ultrasound applicators have been developed for delivery of hyperthermia or high-temperature thermal ablation of cancer and benign disease of the prostate. ${ }^{33}$ These devices allow for control of heating during delivery of therapy. Using a canine model, it was demonstrated that catheter-based ultrasound devices combined with magnetic resonance thermal monitoring can achieve relatively rapid and accurate thermal ablation of the prostate. ${ }^{34}$

\section{Transurethral water vapor therapy: the Rezum system}

The Rezum system (NxThera, Maple Grove, MN, USA) is a novel, minimally invasive ablative transurethral therapy. It delivers targeted and controlled doses of stored thermal energy directly to the transition zone of the prostate gland to treat BPH by using sterile water vapor. A narrow sheath, similar in size and shape to a cystoscope, is inserted via the urethra and positioned between the bladder neck and the seminal colliculus within the prostatic urethra. A thin needle is deployed through the urethra into the hyperplastic transition zone. Water vapor is delivered rapidly (in 8-10 seconds) and directly into the hyperplastic zone, and is immediately dispersed through the tissue interstices. When the water vapor comes into contact with the prostatic tissue, it condenses into its liquid state and releases its stored thermal energy. This thermal energy denatures the cell membranes immediately, causing instantaneous cell death. The first-inman trial was a dose-ranging study ${ }^{35}$ in which the energy delivered ranged from 190 to 289 calories per injection. In the Rezum I pilot study, all patients received the same dose of 208 calories per injection. For $30-80 \mathrm{~mL}$ prostates, a total of 2-6 administrations were delivered, with a total treatment time of $<90$ seconds. Gadolinium-enhanced MRI T2 imaging, performed in all subjects $(\mathrm{n}=30)$ at 1 week, 1 month, and 3 months following the procedure showed that the lesions, transition zone, and overall prostate size decreased by a mean of $89 \%, 32 \%$, and $26 \%$, respectively. The authors reported a significant improvement in International Prostate Symptom Score (IPSS), quality of life, $Q \max$, and post-void residual at 3 months, which remained stable at follow-up 1 year later. They concluded that this outpatient or office-based procedure is rapid, safe, and effective. Controlled ablation of prostatic tissue was also demonstrated. Another single-center study with a limited follow-up period (3 months) confirmed these promising data. ${ }^{36}$ At present, this system is considered to be an investigational device, and there is one prospective, randomized, controlled, single-blind clinical trial underway in the USA (ClinicalTrials.gov identifier NCT01912339) evaluating the efficacy and safety of the Rezum system and assessing its effect on urinary symptoms secondary to BPH. The estimated study completion date is in June 2019.

\section{Mechanical devices}

Another attractive mechanism for treating BPH/LUTS is to maintain urethral patency using specific designed mechanical devices. The first mechanical device to relieve urethral 
obstruction was used in $1980 .{ }^{37}$ It was made of a metal alloy and initially called a "partial catheter". Subsequently, manufacturers developed various types of catheters, described as prostatic stents, by modifying the design, the compounds used, the biocompatibility, the rigidity, and ease of insertion and removal. Recently, a novel device was invented to mechanically "hold open" the prostatic urethra, ie, the prostatic urethral lift. ${ }^{38}$ Table 2 summarizes the most commonly used prostatic stents.

\section{Prostatic stents}

The use of metallic stents to maintain luminal patency is a well established concept in surgical practice. Its first reported use in urology dates back to the 19th century. Various metallic stents now exist and can be classified into two groups, ie, permanent epithelializing stents and temporary nonepithelializing stents. The latter have the advantage of being able to be inserted in a compressed state, minimizing the risk of urethral injury and the associated pain. The radial force exerted by these stents should theoretically prevent stent migration, and the wider lumen should provide a better urinary flow or even further endourethral maneuver. Their ease of removal makes these stents the first choice for diagnostic purposes and for the treatment of elderly frail patients, as well as use as an adjunct to other minimally invasive treatments for BPH such as thermotherapy, to allow voiding while procedure-related edema resolves. On the other hand, epithelialization of the spiral coil stent had the theoretical advantage of reducing the rate of migration, infection, and encrustation. The major drawbacks of such devices are their limited tolerability under local anesthesia and the difficulties associated with their removal. The Urospiral ${ }^{\circledR}$ stent (Porges, Paris, France), the first stent used in humans, was inserted endoscopically between the bladder neck and the seminal

Table 2 Characteristics of commonly used prostatic stents

\begin{tabular}{|c|c|c|c|c|c|}
\hline & Trademark & Composition & $\begin{array}{l}\text { Lumen } \\
\text { (French) }\end{array}$ & $\begin{array}{l}\text { Length } \\
(\mathrm{mm})\end{array}$ & Opening \\
\hline \multicolumn{6}{|l|}{ Metal stent } \\
\hline \multicolumn{6}{|c|}{ A. Epithelializing/permanent stents } \\
\hline - Urolume Wallstent & $\begin{array}{l}\text { American Medical Systems, } \\
\text { Minnetonka, MN, USA }\end{array}$ & $\begin{array}{l}\text { Biocompatible superalloy } \\
\text { woven tubular mesh }\end{array}$ & 42 & $20-30$ & Self-expandable \\
\hline - Memotherm & Bard, Covington, KT, USA & $\begin{array}{l}\text { Nitinol woven } \\
\text { single wire }\end{array}$ & $36 / 42$ & $15-80$ & Heat expandable \\
\hline \multicolumn{6}{|c|}{ B. Non-epithelializing/temporary stents } \\
\hline \multicolumn{6}{|l|}{ - First-generation } \\
\hline - Urospiral stent & Porges, Paris, France & Stainless steel & 21 & $40-80$ & Self-expandable \\
\hline - Prostakath & $\begin{array}{l}\text { Engineers and Doctors, } \\
\text { Copenhagen, Denmark }\end{array}$ & $\begin{array}{l}\text { Gold-plated } \\
\text { stainless steel }\end{array}$ & 21 & $35-95$ & Self-expandable \\
\hline \multicolumn{6}{|l|}{ - Second-generation } \\
\hline \multicolumn{5}{|l|}{ - Third-generation } & Self-expandable \\
\hline - Memokath stent & $\begin{array}{l}\text { Doctors and Engineers, } \\
\text { Kvistjaard, Denmark }\end{array}$ & Nitinol & $22-44$ & $35-95$ & Heat-expandable \\
\hline - Z-stent & $\begin{array}{l}\text { Wilson-Cook Medical, } \\
\text { Winston-Salem, NC, USA }\end{array}$ & Gold-plated stainless steel & 30 & $30-60$ & Self-expandable \\
\hline \multicolumn{6}{|l|}{ - Fourth-generation } \\
\hline - Allium prostatic stent & Allium Corporation, Israel & $\begin{array}{l}\text { Nitinol wire covered with } \\
\text { a biocompatible co-polymer }\end{array}$ & 45 & $30-65$ & Self-expandable \\
\hline \multicolumn{6}{|l|}{ Non-metal stent } \\
\hline \multicolumn{6}{|l|}{ A. Plastic stents } \\
\hline - Spanner stent & $\begin{array}{l}\text { Abbey Moor Medical, } \\
\text { Parkers Prairie, MN, USA }\end{array}$ & Polyurethane & 20 & $40-90$ & As a Foley catheter \\
\hline - Intraurethral catheter & $\begin{array}{l}\text { Angiomed Company Ltd, } \\
\text { Karlsruhe, Germany }\end{array}$ & Puroflex & $16-18$ & $25-80$ & \\
\hline - Barnes stent & Angiomed, Bard, UK & Polyurethane & 16 & 50 & \\
\hline - Trestle stent & $\begin{array}{l}\text { Boston Scientific Microvasive } \\
\text { Natick, MA, USA }\end{array}$ & Polyurethane & 22 & 75 & \\
\hline \multicolumn{6}{|l|}{ B. Biodegradable stents } \\
\hline - Biofix & $\begin{array}{l}\text { Bionx Implants, } \\
\text { Tampere, Finland }\end{array}$ & $\begin{array}{l}\text { Polyglycolic acid, } \\
\text { polylactic acid }\end{array}$ & $21-24$ & $45-85$ & Self-expandable \\
\hline
\end{tabular}


colliculus to preserve luminal patency and alleviate bladder outlet obstruction secondary to $\mathrm{BPH} .{ }^{37}$ Despite encouraging short-term outcomes, migration, and encrustation in the stent lumen precludes its use by urologists. A popular and better studied epithelializing stent is the Urolume Wallstent ${ }^{\circledR}$ (American Medical Systems, Minnetonka, MN, USA). In a systematic review from 2007, 84\% of catheter-dependent patients voided spontaneously. ${ }^{39}$ However, one in six men needed the stent to be removed within 1 year because of malpositioning, migration, penile pain, and symptoms of irritation. Soon after, another permanent metal stent became available, ie, the thermoexpandable Memotherm ${ }^{\circledR}$ stent (Bard, Covington, KT, USA). However, studies demonstrated a similar rate of complications. ${ }^{40}$ The same results were reported with the Prostakath ${ }^{\circledR}$ (Engineers and Doctors, Copenhagen, Denmark). ${ }^{41}$ A second-generation of metal stents was developed to prevent encrustation and migration and to allow a much longer indwelling time. ${ }^{42}$ Refinements to these stents resulted in the development of thermoexpandable stents, such as the Memokath ${ }^{\circledR}$ stent (Doctors and Engineers, Kvistjaard, Denmark), which is a nickel-titanium alloy spiral stent with the main advantage of ease of removal based on its physical properties at different temperatures. ${ }^{43}$ The ability to correctly insert this stent under fluoroscopy and transrectal ultrasound without the need for cystoscopy was also demonstrated. ${ }^{44}$ Another self-expandable metallic device, the Z-stent ${ }^{\circledR}$ (Wilson-Cook Medical, Winston-Salem, NC, USA) was developed to be inserted under fluoroscopic guidance only. ${ }^{45}$ Clinical studies had demonstrated safety, tolerability, and short-term efficacy for the Memokath stent. ${ }^{46}$ However, migration was still a major limitation to widespread acceptance of these stents. Manufacturers tried to change the shape of these cylindrical stents. However, the hourglassshaped and bell-shaped Memokath stents also had the same rate of migration. ${ }^{47,48}$ To avoid this, Markovic et al designed the triangular prostatic stent, which conforms well to the prostatic urethral lumen shape, and reported no migration at 9 months of follow-up. A plastic coating was also added to prevent encrustation. ${ }^{49}$

Refinements in temporary prostatic stents resulted in the development of biodegradable stents and polyurethane intraurethral catheters. The polyurethane Spanner ${ }^{\circledR}$ prostatic stent (Abbey Moor Medical, Parkers Prairie, MN, USA) was initially developed for temporary use only. ${ }^{50}$ The early experimental and clinical test outcomes provided reasonable assurance that the Spanner stent is safe and effective when used as an adjunct to minimally invasive therapies. ${ }^{51}$ Corica et al easily inserted and removed the stent under topical anesthesia in 30 patients. They reported a significant improvement in IPSS, post-void residual, and $Q \max$, with no changes in voiding and continence. The authors confirmed the stability, patency, and lack of migration of the device on imaging during up to 12 weeks of use. However, its primary use in patients unfit for surgery was unsatisfactory, with only $37 \%$ of the patients continuing to have a stent in situ after a mean of five changes (every 3 months) or being stent-free after a successful voiding trial. ${ }^{52}$ More recently, the properties of stents had been manipulated by using biodegradable materials such as polylactic acid, polyglycolic acid, and copolymers of lactide and glycolide to allow a longer degradation time. The main advantage of biodegradable stents is their spontaneous degradation and absorption without the need of removal. The most clinical utility of these stents is seen when they are used in combination with 5-alpha reductase inhibitors. ${ }^{53}$ The spiral configuration of the first biodegradable stents was modified later on by researchers for a tubular mesh stent to decrease the risk of displacement and collapse as well as obstruction associated with breakage into large particles. Kotsar et al successfully treated ten patients with acute urinary retention by inserting a biodegradable braided urethral stent combined with dutasteride. All men were able to void after insertion of the stent and at 3 months $50 \%$ of patients were voiding with no problems. ${ }^{54}$

\section{Prostatic urethral lift}

The US Food and Drug Administration recently approved the marketing of a new device (UroLift ${ }^{\circledR}$, Neo Tract Inc., Pleasanton, CA, USA) offering an attractive novel mechanism to treat the enlarged prostate. Nonabsorbable monofilament sutures and a nitinol capsular tab are positioned from the urethra to the outer fibrous capsule in order to pull the lateral lobes of the prostate toward the capsule through permanent tensioning. A recent comprehensive review concluded that the UroLift system is superior to medical therapy for the improvement of LUTS but inferior to surgery. ${ }^{55}$ Apart from being a short, well tolerated procedure performed under local anesthesia and sedation in an outpatient setting, the major advantage of this system is the absence of erectile or ejaculatory dysfunction after treatment. ${ }^{55}$ In contrast, sexual function improved significantly at 1 year. ${ }^{56}$ This could be understandably attributed to the absence of neurovascular bundle thermal injury and preservation of the bladder neck. Another attribute of this technology is the significant rapid and sustained relief from obstruction without the need for postoperative catheterization and low complication rates, as demonstrated by two multicenter, prospective, randomized blind clinical trials. ${ }^{57,58}$ In the 
first study, ie, the Luminal Improvement Following Prostatic Tissue Approximation trial, patient treated with the UroLift experienced a AUASI (American Urological Association Symptom Index) reduction from 22.1 at baseline to 18.0, 11.0, and 11.1 at 2 weeks, 3 months, and 12 months, respectively $(P<0.001)$. Peak urinary flow rate increased to $4.4 \mathrm{~mL}$ per second at 3 months and was sustained at $4.0 \mathrm{~mL}$ per second at 12 months $(P<0.001)$. Adverse events were typically mild and transient, with no occurrence of de novo ejaculatory or erectile dysfunction. ${ }^{57}$ The second study had a different design, being a crossover study. It confirmed the outcomes of the first study, and showed that an UroLift procedure has no impact on subsequent use of TURP or laser therapy for $\mathrm{BPH} .{ }^{58}$ Of note, patients included in the two clinical trials had a prostatic volume $<80 \mathrm{~mL}$, and long-term data beyond 3 years are lacking.

\section{Fractionation of prostatic tissue}

This novel concept is based on the development of new technologies able to deliver high intensity energy enough to cause tissue emulsification without thermal effects. Two cutting edge technologies are under development, and are considered as experimental treatments under investigation, ie, histotripsy and aquablation.

\section{Emulsification of prostate tissue by histotripsy}

The word histotripsy is derived from the Greek, meaning breakdown of soft tissue. This technique was initially conceived and developed at the University of Michigan. It uses acoustic energy in the form of short ( $<50$ microseconds) very high intensity pulses that induce controlled cavitation clouds to mechanically homogenize the targeted tissue. The physical mechanism is similar to shockwave lithotripsy; each histotripsy pulse creates a localized highly dynamic cluster of microbubbles, the energetic interaction of which with tissue produces a fraction of the required tissue fragmentation or emulsification with cellular and tissue disruption, and subsequent pulses for bubble regeneration. In an in vivo rabbit model, by increasing the numbers of histotripsy pulses, small foci of homogenized tissue enlarged and merged with adjacent foci to finally produce a liquefied core of cytoplasm and fractionated debris with no discernible cellular structure surrounded by sharp smooth boundaries only a few millimeters wide. ${ }^{59}$ This process is self-limited after 1,000 pulses. ${ }^{59}$ However, its efficiency could be increased further by using techniques to remove the bubble nuclei that persist between pulses, as recently demonstrated by Wang et al. ${ }^{60}$ Unlike ther- mal ablative techniques, this cavitational mechanical effect is independent of temperature, as evidenced by an ex vivo porcine kidney model. ${ }^{61}$ The lack of heating as a mechanism for tissue destruction is the major distinction between histotripsy and HIFU. This principle has been confirmed with another recently proposed method of tissue emulsification by shock wave heating, ie, boiling histotripsy, which has the advantage to be less stochastic in its occurrence than cavitation, which makes the method utilizing boiling more predictable and repeatable. ${ }^{62}$ It had also been demonstrated in a canine model that the liquid consistency of the tissue after prostate histotripsy facilitates drainage via the urethra and results in minimal damage to surrounding tissues and blood vessels. ${ }^{62}$ This high precision was demonstrated in a phantom prostate composed of red blood cells and agar. By applying preconditioning pulses to delete bubble nuclei at the periphery of the targeted volume, Wang et al were able to further increase their accuracy on the target. ${ }^{63}$ Of note, these microbubble clouds are excellent sound reflectors and allow transrectal monitoring of treatment progression by ultrasound in real time. Lake et al investigated the potential of histotripsy as a minimally invasive therapy for $\mathrm{BPH}$, and reported the initial results for ablation of prostatic tissue using histotripsy in an in vivo canine model. ${ }^{64}$ Histotripsy was capable of precise prostatic tissue destruction and produced prostatic urethral damage, thereby facilitating drainage of fractionated material per the urethra and producing immediate debulking, as demonstrated by retrograde urethrography and histology. However, the periurethral prostatic tissues were more resilient to emulsification than their glandular counterparts and required higher doses. This lead Schade et al to develop urethral sparing histotripsy. ${ }^{65}$ They demonstrated effective homogenization and a $12 \%$ decrease in prostatic volume. In another study of nine anticoagulated canine subjects, Wheat et al suggested that histotripsy is safe and may induce hemostatic effects. ${ }^{66}$ Another study investigated the local and systemic effects of histotripsy in 18 canine subjects, ${ }^{67}$ and reported the treatment to be safe and well tolerated, except in one case where a rectourethral fistula developed, with the rectum being inadvertently treated on several occasions. The relative susceptibility of the rectum when compared with the sphincter, neurovascular bundles, the bladder neck and the ureteral orifices was demonstrated in two other studies aiming to determine the thresholds of injury for surrounding tissues. ${ }^{68,69}$ An important consideration in translating histotripsy for the treatment of BPH in humans is the availability of an acoustic window to access and monitor the prostate. For most canines, the prostate is located cranial to the pubis, which makes the 
transabdominal approach relatively straightforward. The human prostate is located deeper within the pelvis and closer to the perineum, which is why a transperineal approach is superior, as demonstrated by a recent study. ${ }^{70}$ In general, the transrectal approach is preferred by the urologist. However, the transducer surface area needed to initiate cavitation clouds is larger than the size of the rectum. Future evolution of piezoelectric technology should result in miniaturization of the probe, allowing the transrectal approach. The concept of this new technology is appealing, and in order to move beyond the proof of concept, a human prototype device has been developed (Vortx Rx ${ }^{\mathrm{TM}}$, HistoSonics Inc., Ann Arbor, MI, USA). This device was approved by the US Food and Drug Administration for a human pilot study (ClinicalTrials. gov identifier NCT01775488) designed to assess and monitor the safety and efficacy of the Vortx Rx for the treatment of BPH. However, this study has been suspended because of poor recruitment.

\section{Aquablation using water jet hydrodissection}

The Procept aquablation system (Procept Biorobotics Corp, Redwood Shores, CA, USA) is a newly developed cuttingedge technology. It is an integrated system using a highvelocity saline stream delivered under precise motion control to selectively ablate prostatic glandular tissue while sparing the blood vessels and capsule. Once the ablation is complete, a laser built into the water jet (Aquabeam ${ }^{\mathrm{TM}}$ ) can be used to produce surface hemostasis with a very low laser power $(2-4 \mathrm{~W})$. The extent, depth of ablation, and real time monitoring is predetermined by endoscopic and transrectal ultrasound guidance. The hypothetical advantage is a rapid fractionation of tissue without thermal injury and with minimal bleeding. ${ }^{71}$ This new technology has been established as safe in dogs, and there is one ongoing pilot study on humans (Australian New Zealand Clinical Trials Registry identifier ACTRN12613000167763).

\section{Percutaneous transluminal prostate artery embolization}

Prostate artery embolization (PAE) involves the introduction of microparticles (polyvinyl alcohol, trisacryl gelatin microspheres, or other synthetic biocompatible materials) into the prostatic arteries via a percutaneous transfemoral approach, thereby blocking blood flow to the prostate and inducing partial necrosis and shrinkage. ${ }^{72,73}$ In 1980, Darewicz et al demonstrated ischemic changes occurring in the prostate gland following internal iliac artery embolization in the dog. ${ }^{74}$
They first defined the indication for internal iliac artery embolization to be used in clinical practice as a method for treating hemorrhage from the prostatic gland. DeMeritt et al described a patient with $\mathrm{BPH}$ who had severe gross hematuria and underwent prostatic arterial embolization. ${ }^{75}$ The patient stopped bleeding and the size of the prostate decreased to $52 \%$ and $62 \%$ of its initial size on follow-up 5 and 12 months later. In 2008, an experimental study of PAE in pigs showed a significant reduction in prostate volume without compromising sexual function in the animals. ${ }^{76}$ In 2010, Carnevale et al were the first to describe primary treatment of BPH with PAE. ${ }^{77}$ They successfully treated two patients with acute urinary retention, and reported a $47.8 \%$ and $27.8 \%$ reduction in prostate size for bilateral PAE and unilateral PAE, respectively, at the 6-month follow-up. Subsequently, one prospective randomized controlled trial and several uncontrolled pilot studies with limited numbers of patients had been reported, with promising results. ${ }^{78-81}$ The largest prospective non-randomized case series was reported for 255 patients in Portugal. ${ }^{82}$ Technical success was achieved in nearly all these patients, with a clinical success rate of $82 \%$ and $72 \%$ after the 1 st month and 3 years, respectively. Both clinical and urodynamic parameters improved with PAE. The authors described the technique well, ie, that it involves assessment of the prostatic and pelvic arterial anatomy by performing computed tomographic angiography before the intervention. ${ }^{83}$ This allows identification of anatomical variants, avoidance of collaterals to adjacent organs, planning for targeted superselective catheterization of small prostatic arteries, and avoidance of unsuitable cases with small size vessel, excessive kinking, and/or atherosclerosis. Development of small microcatheters (2.4 French or even smaller) and catheters with a pear-shaped tip allowed experienced operators to overcome most of these anatomical difficulties. Non-target embolization had been demonstrated to cause transient ischemic proctitis and bladder wall necrosis. ${ }^{84}$ The authors suggested performing a proximal embolization first and then a second step of distal embolization to complete occlusion and stasis of blood flow to the prostatic tissue. ${ }^{85}$ Clinical improvement after PAE is not fully predictable, and up to $15 \%$ of patients may have a poor outcome. ${ }^{86}$ Recently, de Assis et al reported the results of their prospective, single-center, single-arm study conducted in 35 patients. ${ }^{87}$ The development of infarcts and volume reduction following embolization is reported to be higher than $70 \%$ and is well assessed by MRI. ${ }^{88}$ The poor correlation between prostatic volume and clinical improvement suggests potential contribution of a mechanism other than reduction of prostatic volume. 
In addition, the prostate volume may not be related to the severity of obstruction. This explains why unilateral embolization in some studies may achieve significant symptomatic improvement even with lower volume reduction. ${ }^{85}$ Recently, the results of a prospective randomized trial comparing the efficiency and safety of PAE with that of TURP were published. ${ }^{89}$ The authors found no significant differences in functional urinary outcomes $(P<0.001)$. IPSS, quality of life, $Q$ max, and post-void residual volume showed improvement in both groups. However, the improvement occurred significantly earlier in the TURP group than in the PAE group. The decreases in prostate-specific antigen (PSA) and prostate volume were significantly greater in the TURP group $(P<0.05)$, and the PAE group showed more overall adverse events and complications ( $P=0.029)$, ie, acute urinary retention, post-embolization syndrome, and technical failures.

At present, PAE is still considered to be an experimental treatment modality for BPH and patients should be encouraged to participate in clinical trials. To our knowledge, there are currently three ongoing prospective randomized trials recruiting. An open-label interventional trial recruiting since June 2014 in the USA (ClinicalTrials.gov identifier NCT02167919) is aiming to evaluate the efficacy of PAE in decreasing the volume of the prostate $(>80 \mathrm{~mL})$ in patients with refractory LUTS/BPH (IPSS $>18$ ). The UKROPE (Registry of Prostate Embolization) and a Swiss trial (ClinicalTrials.gov identifier NCT02054013) are designed as prospective, randomized, non-inferiority trials comparing the effects of treatment and adverse events for PAE and TURP.

\section{Intraprostatic drugs}

The concept of intraprostatic injection dates back to 1832 . In 1910, intraprostatic injection was used for the first time as a minimally invasive alternative to treat BPH. ${ }^{90}$ In 1966 , Talwar and Pande obtained favorable results using a solution of glycerin, glacial acetic acid, and carbolic acid in 188 consecutive patients with acute urinary retention. ${ }^{91}$ Subsequently, these researchers used several chemical compounds in both animal and clinical studies with encouraging outcomes. The mechanism of action of intraprostatic injection was also partially described. It was demonstrated that these injections decrease the prostate volume by inducing apoptosis and tissue necrosis and act on afferent nerves to alleviate obstruction and improve LUTS. ${ }^{92}$ The technique lost popularity until the last decade. This is partially explained by a shift of focus in the clinical understanding and management of LUTS from the prostate to the bladder.
Growing experience first developed interest in intraprostatic ethanol injections, which is to date the most widely investigated intraprostatic therapy. A recent review showed significant improvement in symptom scores, $Q$ max, post-void residual, and quality of life. ${ }^{92}$ The post-injection perineal pain associated with extraprostatic extravasations substantially diminished after the advent of transrectal ultrasound and understanding of the anatomical landmarks. ${ }^{92}$ Changing the route of administration to transrectal and inclusion of periprostatic nerve block makes the procedure more tolerable under local anesthesia. Use of anhydrous ethanol instead of liquid ethanol made control of distribution more accurate, thereby decreasing extravasations and complication rates. ${ }^{93}$ The first investigational new drug study assessed the safety and efficacy of a novel system using a curved cystoscopic needle delivery device (Prostaject, American Medical Systems) to administer anhydrous ethanol transurethrally. ${ }^{94}$ The safety, tolerability, and initial efficacy were demonstrated. However, rare serious events and complications and considerable retreatment rates ( $41 \%$ after 3 years) preclude its current use in clinical practice..$^{95}$

In the last decade, there has been growing interest in intraprostatic injection of botulinum toxin for the treatment of LUTS/BPH. Although the mechanism of action was attractive with promising results reported initially, the largest, placebocontrolled, double-blind trial on the efficacy of botulinum toxin in men with LUTS/BPH showed no significant difference between botulinum toxin and placebo in terms of IPSS (41\% versus $13 \%$ ), quality of life, $Q \max (33 \%$ versus $13 \%$ ), and prostate volume (14\% versus $7 \%) .{ }^{96}$ On post hoc analysis, a significant reduction in IPSS versus placebo was observed with onabotulinumtoxinA in prior alpha-blocker users. Adverse events were comparable across all groups. At present, more basic research is needed to understand the mechanism of action of this toxin.

NX-1207 is administered as a clinic-based procedure via ultrasound-guided transrectal intraprostatic injection and causes apoptotic cell death. Phases I and II clinical trials have demonstrated a significant treatment effect for LUTS/BPH. NX-1207 has not shown any of the bothersome and limiting sexual side effects of the oral therapies. Two large Phase III trials are ongoing to further confirm the efficacy, safety, and tolerability of this catheter on anesthetic-free procedure. ${ }^{97}$

PRX302 is a modified form of proaerolysin; highly toxic bacterial pore-forming protons activated by PSA with the ability to effectively and safely ablate PSA-producing prostate tissue. PRX302 is injected transperineally under transrectal ultrasound guidance. Phase I and II studies have 
also demonstrated improvement in IPSS, quality of life, and prostate volume with no deleterious effect on sexual function. $^{98}$

A recent Phase IIb trial reported that this outpatient-based procedure was well tolerated with statistically significant improvement in patient subjective (IPSS) and quantitative objective $(Q \max )$ measures sustained during 12 months of follow-up. ${ }^{99}$ Adequately powered, randomized, placebocontrolled, blinded studies with long-term follow-up are still needed before intraprostatic injection can be considered a suitable therapeutic option in contemporary clinical practice. The concept of intraprostatic injections of different agents as a minimally invasive surgical therapy for LUTS /BPH is attractive, but thus far the results available are unclear.

\section{Conclusion}

The concept of new minimally invasive procedures combined with technical advances and refinements is attractive as a method for alleviating some of the concerns regarding minimally invasive procedures. Recently, several new approaches have emerged. Some of these techniques had already shown safety and efficacy for the treatment of LUTS/BPH with the advantage of being able to be performed as an outpatient procedure under local anesthesia with no sexual adverse events. Other procedures are to date considered as experimental and under clinical investigation. More systematic laboratory research and currently ongoing clinical trials need to be completed to elucidate the potential role of these newer devices for the treatment of LUTS/BPH.

\section{Disclosure}

The authors report no conflicts of interest in this work.

\section{References}

1. Levy A, Samraj GP. Benign prostatic hyperplasia: when to 'watch and wait,' when and how to treat. Cleve Clin J Med. 2007;74:S15-S20.

2. Djavan B, Fong YK, Harik M, et al. Longitudinal study of men with mild symptoms of bladder outlet obstruction treated with watchful waiting for four years. Urology. 2004;64:1144-1148.

3. Pagano E, Laudato M, Griffo M, Capasso R. Phytotherapy of benign prostatic hyperplasia. A mini review. Phytother Res. 2014;28:949-955.

4. Oelke M, Bachmann A, Descazeaud A, et al. EAU guidelines on the treatment and follow-up of non-neurogenic male lower urinary tract symptoms including benign prostatic obstruction. Eur Urol. 2013;64:118-140.

5. Rassweiler J, Teber D, Kuntz R, Hofmann R. Complications of transurethral resection of the prostate (TURP) - incidence, management, and prevention. Eur Urol. 2006;50:969-979.

6. Yerushalmi A, Fishelovitz Y, Singer D, et al. Localized deep microwave hyperthermia in the treatment of poor operative risk patients with benign prostatic hyperplasia. J Urol. 1985;133:873-876.

7. Montorsi F, Galli L, Guazzoni G, et al. Transrectal microwave hyperthermia for benign prostatic hyperplasia: long-term clinical, pathological and ultrastructural patterns. $J$ Urol. 1992;148:321-325.
8. Larson TR, Collins JM, Corica A. Detailed interstitial temperature mapping during treatment with a novel transurethral microwave thermoablation system in patients with benign prostatic hyperplasia. J Urol. 1998;159:258-264.

9. Netto NR, Claro JA. Traitement de l'hypertrophie bénigne de prostate par Prostatron ${ }^{\circledR}$ : étude des effets d'une augmentation de la température de traitement. [Treatment of benign prostate hypertrophy using prostatron: a study of the effects of treatment temperature elevation]. Prog Urol. 1995;5:238-244. French.

10. Larson TR, Blute ML, Tri JL, Whitlock SV. Contrasting heating patterns and efficiency of the Prostatron and Targis microwave antennae for thermal treatment of benign prostatic hyperplasia. Urology. 1998;51:908-915.

11. Walmsley K, Kaplan SA. Transurethral microwave thermotherapy for benign prostate hyperplasia: separating truth from marketing hype. J Urol. 2004;172:1249-1255.

12. Larson TR, Blute ML, Bruskewitz RC, et al. A high-efficiency microwave thermoablation system for the treatment of benign prostatic hyperplasia: results of a randomized, sham-controlled, prospective, double-blind, multicenter clinical trial. Urology. 1998;51:731-742.

13. Roehrborn CG, Preminger G, Newhall P, et al. Microwave thermotherapy for benign prostatic hyperplasia with the Dornier Urowave: results of a randomized, double-blind, multicenter, sham controlled trial. Urology. 1998;51:19-28.

14. Ramsey EW, Miller PD, Parsons K. A novel transurethral microwave thermoablation system to treat benign prostatic hyperplasia: results of a prospective multicenter clinical trial. J Urol. 1997;158:112-119.

15. Hoffman RM, Monga M, Elliott SP, et al. Microwave thermotherapy for benign prostatic hyperplasia. Cochrane Database Syst Rev. 2012;9: CD004135.

16. Kaye JD, Smith AD, Badlani GH, et al. High-energy transurethral thermotherapy with Core Therm approaches transurethral prostate resection in outcome efficacy: a meta-analysis. J Endourol. 2008;22: 713-718.

17. Djavan B, Fakhari M, Shariat $S$, et al. A novel intraurethral prostatic bridge catheter for prevention of temporary prostatic obstruction following high-energy transurethral microwave thermotherapy in patients with benign prostatic hyperplasia. J Urol. 1999;161:144-151.

18. Djavan B, Shariat S, Fakhari M, et al. Neoadjuvant and adjuvant alpha-blockade improves early results of high-energy transurethral microwave thermotherapy for lower urinary tract symptoms of benign prostatic hyperplasia: a randomized, prospective clinical trial. Urology. 1999;53:251-259.

19. Djavan B, Shariat S, Schäfer B, Marberger M. Tolerability of high energy transurethral microwave thermotherapy with topical urethral anesthesia: results of a prospective, randomized, single-blinded clinical trial. J Urol. 1998;160:772-776.

20. Cormio L, Bloem F, Laduc R, Debruyne FMJ. Pain sensation in transurethral microwave thermotherapy for benign prostatic hyperplasia: the rationale for prophylactic sedation. Eur Urol. 1994;25:36-39.

21. Bartoletti R, Meliani E, Simonato A, et al. Microwave-induced thermoablation with Amica-probe is a safe and reproducible method to treat solid renal masses: results from a phase I study. Oncol Rep. 2012;28:1243-1248.

22. Xylinas E, Le Gal S, Descazeaud A. Transurethral needle ablation Prostiva for treating symptomatic benign prostatic hyperplasia: a review. Prog Urol. 2010;20:566-571.

23. Bouza C, Lopez T, Magro A, et al. Systematic review and meta-analysis of transurethral needle ablation in symptomatic benign prostatic hyperplasia. BMC Urol. 2006;6:14.

24. El-Husseiny T, Buchholz N. Transurethral ethanol ablation of the prostate for symptomatic benign prostatic hyperplasia: long-term follow-up. J Endourol. 2011;25:477-480.

25. Hill B, Belville W, Bruskewitz R, et al. Transurethral needle ablation versus transurethral resection of the prostate for the treatment of symptomatic benign prostatic hyperplasia: 5-year results of a prospective, randomized, multicenter clinical trial. J Urol. 2004;171:2336-2340.

26. Ebbing J, Bachmann A. Anesthesia-free procedures for benign prostate obstruction: worth it? Curr Opin Urol. 2015;25:32-39. 
27. Leoci R, Aiudi G, Silvestre F, Lissner E, Lacalandra GM. Effect of pulsed electromagnetic field therapy on prostate volume and vascularity in the treatment of benign prostatic hyperplasia: a pilot study in a canine model. Prostate. 2014;74:1132-1141.

28. Giannakopoulos XK, Giotis C, Karkabounas SCh, et al. Effects of pulsed electromagnetic fields on benign prostate hyperplasia. Int Urol Nephrol. 2011;43:955-960.

29. Madersbacher S, Kratzik C, Susani M, et al. Tissue ablation in benign prostatic hyperplasia with high intensity focused ultrasound. $J$ Urol. 1994;152:1956-1960.

30. Sanghvi NT, Foster RS, Bihrle R, et al. Noninvasive surgery of prostate tissue by high intensity focused ultrasound: an updated report. Eur $J$ Ultrasound. 1999;9:19-29.

31. Uchida T, Muramoto M, Kyunou H, Iwamura M, Egawa S, Koshiba K. Clinical outcome of high intensity focused ultrasound for treating benign prostatic hyperplasia: preliminary report. Urology. 1998;52: 66-71.

32. Diederich CJ, Nau WH, Ross AB, et al. Catheter-based ultrasound applicators for selective thermal ablation: progress towards MRI-guided applications in prostate. Int J Hyperthermia. 2004;20:739-756.

33. Tyréus PD, Nau WH, Diederich CJ. Effect of applicator diameter on lesion size from high temperature interstitial ultrasound thermal therapy. Med Phys. 2003;30:1855-1863.

34. Diederich CJ, Nau WH, Kinsey A, et al. Catheter-based ultrasound devices and MR thermal monitoring for conformal prostate thermal therapy. Conf Proc IEEE Eng Med Biol Soc. 2008;2008: 3664-3668.

35. Dixon C, Rijo Cedano E, Pacik D, et al. Transurethral water vapor therapy for BPH; initial clinical results of the first in man trial and Rezum I pilot study. Eur Urol Suppl. 2013;12:e631.

36. Chung A, Woo HH. What's truly minimally invasive in benign prostatic hyperplasia surgery? Curr Opin Urol. 2014;24:36-41.

37. Fabian KM. [The intra-prostatic 'partial catheter' (urological spiral)]. Urologe A. 1980;19:236-238. German.

38. Woo HH, Chin PT, McNicholas TA, et al. Safety and feasibility of the prostatic urethral lift: a novel, minimally invasive treatment for lower urinary tract symptoms (LUTS) secondary to benign prostatic hyperplasia (BPH). BJU Int. 2011;108:82-88.

39. Armitage JN, Cathcart PJ, Rashidian A, De Nigris E, Emberton M, van der Meulen JH. Epithelializing stent for benign prostatic hyperplasia: a systematic review of the literature. $J$ Urol. 2007;177: 1619-1624.

40. Uchikoba T, Horiuchi K, Satoh M, et al. [Urethral stent (AngiomedMemotherm) implantation in high-risk patients with urinary retention] Hinyokika Kiyo. 2005;51:235-239. Japanese.

41. Braf Z, Chen J, Sofer M, Matzkin H. Intraprostatic metal stents (Prostakath and Urospiral): more than 6 years' clinical experience with 110 patients. $J$ Endourol. 1996;10:555-558.

42. Yachia D, Aridogan IA. Comparison between first-generation (fixed caliber) and second-generation (self-expanding, large caliber) temporary prostatic stents. Urol Int. 1996;57:165-169.

43. Staios D, Shergill I, Thwaini A, et al. The Memokath ${ }^{\mathrm{TM}}$ stent. Expert Rev Med Devices. 2007;4:99-101.

44. Minagawa T, Murata Y, Seki S. [Placement of a shape-memory alloy intraurethral catheter (Memokath) using transrectal ultrasonography and fluoroscopy]. Nippon Hinyokika Gakkai Zasshi. 2009;100:508-512. Japanese.

45. Song HY, Cho KS, Sung KB, et al. Self-expandable metal stents in high risk patients with benign prostatic hyperplasia: long-term follow-up. Radiology. 1995;95:655-660.

46. Armitage JN, Rashidian A, Cathcart PJ, et al. The thermo-expandable metal stent for managing benign prostatic hyperplasia: a systematic review. BJU Int. 2006;98:806-810.

47. Van Dijk MM, Mochtar CA, Wijkstra H, et al. Hourglass-shaped nitinol prostatic stent in treatment of patients with lower urinary tract symptoms due to bladder outlet obstruction. Eur Urol. 2006;49: 353-359.
48. Van Dijk MM, Mochtar CA, Wijkstra H, et al. The bell-shaped nitinol prostatic stent in the treatment of lower urinary tract symptoms: experience in 108 patients. Urology. 2005;66:845-849.

49. Marković BB, Marković Z, Yachia D, Hadzi DJ. A new generation of urethral stents: allium in the therapy of symptomatic prostatic enlargement of various etiology. Acta Chir Iugosl. 2007;54:71-76.

50. Vanderbrink BA, Rastinehad AR, Badlani GH. Prostatic stents for the treatment of benign prostatic hyperplasia. Curr Opin Urol. 2007;17:1-6.

51. Grimsley SJ, Khan MH, Lennox E, Paterson PH. Experience with the spanner prostatic stent in patients unfit for surgery: an observational study. J Endourol. 2007;21:1093-1096.

52. Corica AP, Larson BT, Sagaz A, et al. A novel temporary prostatic stent for the relief of prostatic urethral obstruction. BJU Int. 2004;93: 346-348.

53. Papatsoris GA, Junaid I, Zachou A, et al. New developments in the use of prostatic stents. Open Access J Urol. 2011;3:63-68.

54. Kotsar A, Isotalo T, Juuti H, et al. Biodegradable braided poly(lacticcoglycolic acid) urethral stent combined with dutasteride in the treatment of acute urinary retention due to benign prostatic enlargement: a pilot study. BJU Int. 2009;103:626-629.

55. Perera M, Roberts MJ, Doi SA, Bolton D. Prostatic urethral lift improves urinary symptoms and flow while preserving sexual function for men with benign prostatic hyperplasia: a systematic review and metaanalysis. Eur Urol. 2015;67:704-713.

56. Woo HH, Bolton DM, Laborde E, et al. Preservation of sexual function with the prostatic urethral lift: a novel treatment for lower urinary tract symptoms secondary to benign prostatic hyperplasia. $J$ Sex Med. 2012;9:568-575.

57. McVary KT, Gange SN, Shore ND, et al. Treatment of LUTS secondary to BPH while preserving sexual function: randomized controlled study of prostatic urethral lift. J Sex Med. 2014;11:279-287.

58. Cantwell AL, Bogache WK, Richardson SF, et al. Multicentre prospective crossover study of the 'prostatic urethral lift' for the treatment of lower urinary tract symptoms secondary to benign prostatic hyperplasia. BJU Int. 2014;113:615-622.

59. Roberts WW, Hall TL, Ives K, et al. Pulsed cavitational ultrasound: a noninvasive technology for controlled tissue ablation (histotripsy) in the rabbit kidney. $J$ Urol. 2006;175:734-738.

60. Wang T, Xu Z, Hall TL, et al. An efficient treatment strategy for histotripsy by removing cavitation memory. Ultrasound Med Biol. 2012;38:753-766.

61. Kieran K, Hall TL, Parsons JE, et al. Refining histotripsy: defining the parameter space for the creation of non-thermal lesions with high intensity pulsed ultrasound in the in vitro kidney. $J$ Urol. 2007;178:672-676.

62. Wang Y, Khokhlova T, Bailey M, et al. Histological and biochemical analysis of mechanical and thermal bioeffects in boiling histotripsy lesions induced by high intensity focused ultrasound. Ultrasound Med Biol. 2013;39:424-438.

63. Wang T, Xu Z, Hall TL, et al. Active focal zone sharpening for highprecision treatment using histotripsy. IEEE Trans Ultrason Ferroelectr Freq Control. 2011;58:305-315.

64. Lake AM, Hall TL, Kieran K, et al. Histotripsy: minimally invasive technology for prostatic tissue ablation in an in vivo canine model. Urology. 2008;72:682-686.

65. Schade GR, Styn NR, Hall TL, Roberts WW. Endoscopic assessment and prediction of prostate urethral disintegration after histotripsy treatment in a canine model. J Endourol. 2012;26:183-189.

66. Wheat JC, Hall TL, Hempel CR, et al. Prostate histotripsy in an anticoagulated model. Urology. 2010;75:207-211.

67. Hempel CR, Hall TL, Cain CA, Fowlkes JB, Xu Z, Roberts WW. Histotripsy fractionation of prostate tissue: local effects and systemic response in a canine model. $J$ Urol. 2011;185:1484-1489.

68. Styn N, Hall TL, Fowlkes JB, Cain CA, Roberts WW. Histotripsy homogenization of the prostate: thresholds for cavitation damage of periprostatic structures. $J$ Endourol. 2011;25:1531-1535. 
69. Allam CL, Wilkinson JE, Cheng X, Ives KA, Hall TL, Roberts WW. Histotripsy effects on the bladder trigone: functional and histologic consequences in the canine model. J Endourol. 2013;27:1267-1271.

70. Hall TL, Hempel CR, Sabb BJ, Roberts WW. Acoustic access to the prostate for extracorporeal ultrasound ablation. $J$ Endourol. 2010;24:1875-1881.

71. Faber K, de Abreu AL, Ramos P, et al. Image-guided robot-assisted prostate ablation using water jet-hydrodissection: initial study of a novel technology for benign prostatic hyperplasia. J Endourol. 2015;29: 63-69.

72. Bilhim T, Pisco J, Campos Pinheiro L, et al. Does polyvinyl alcohol particle size change the outcome of prostatic arterial embolization for benign prostatic hyperplasia? Results from a single-centre randomized prospective study. J Vasc Interv Radiol. 2013;24:1595-1602.

73. Camara-Lopes G, Mattedi R, Antunes AA, et al. The histology of prostate tissue following prostatic artery embolization for the treatment of benign prostatic hyperplasia. Int Braz J Urol. 2013;39:222-227.

74. Darewicz J, Cylwik B, Musierowicz A, Boczon S. The effect of internal iliac artery embolization of the prostatic gland in the dog. Int Urol Nephrol. 1980;12:37-41.

75. DeMeritt JS, Elmasri FF, Esposito MP, Rosenberg GS. Relief of benign prostatic hyperplasia-related bladder outlet obstruction after transarterial polyvinyl alcohol prostate embolization. J Vasc Interv Radiol. 2000;11:767-770.

76. Sun F, Sanchez FM, Crisostomo V, et al. Benign prostatic hyperplasia: transcatheter arterial embolization as potential treatment - preliminary study in pigs. Radiology. 2008;246:783-789.

77. Carnevale FC, Antunes AA, da Motta Leal Filho JM, et al. Prostatic artery embolization as a primary treatment for benign prostatic hyperplasia: preliminary results in two patients. Cardiovasc Intervent Radiol. 2010;33:355-361.

78. McWilliams JP, Kuo MD, Rose SC, et al. Society of Interventional Radiology position statement: prostate artery embolization for treatment of benign disease of the prostate. J Vasc Interv Radiol. 2014;25: 1349-1351.

79. Golzarian J, Antunes AA, Bilhim T, et al. Prostatic artery embolization to treat lower urinary tract symptoms related to benign prostatic hyperplasia and bleeding in patients with prostate cancer: proceedings from a multidisciplinary research consensus panel. JVasc Interv Radiol. 2014;25:665-674.

80. Bagla S, Cooper JM, Rholl KS, et al. Early findings from a prospective US trial: prostatic artery embolization (PAE) in the treatment of benign prostatic hyperplasia (BPH). J Vasc Interv Radiol. 2013;24 Suppl:74-75.

81. Bagla S, Martin CP, van Breda A, et al. Early results from a United States trial of prostatic artery embolization in the treatment of benign prostatic hyperplasia. J Vasc Interv Radiol. 2014;25:47-52.

82. Pisco JM, Rio Tinto H, Campos Pinheiro L, et al. Embolisation of prostatic arteries as treatment of moderate to severe lower urinary symptoms (LUTS) secondary to benign hyperplasia: results of short- and mid-term follow-up. Eur Radiol. 2013;23:2561-2572.

83. Pisco JM, Pereira J, Rio Tinto H, et al. How to perform prostatic arterial embolization. Tech Vasc Interv Radiol. 2012;15:286-289.
84. Moreira AM, Marques CF, Antunes AA, et al. Transient ischemic rectitis as a potential complication after prostatic artery embolization: case report and review of the literature. Cardiovasc Intervent Radiol. 2013;36:1690-1694.

85. Carnevale FC, Moreira AM, Antunes AA. The "PErFecTED technique": proximal embolization first, then embolize distal for benign prostatic hyperplasia. Cardiovasc Intervent Radiol. 2014;37:1602-1605.

86. Fernandes L, Rio Tinto H, Pereira J, Duarte M, Bilhim T, Martins Pisco J. Prostatic arterial embolization: post-procedural follow-up. Tech Vasc Interv Radiol. 2012;15:294-299.

87. de Assis AM, Moreira AM, de Paula Rodrigues VC, et al. Prostatic artery embolization for treatment of benign prostatic hyperplasia in patients with prostates $>90 \mathrm{~g}$ : a prospective single-center study. J Vasc Interv Radiol. 2015;26:87-93.

88. Frenk NE, Baroni RH, Carnevale FC, et al. MRI findings after prostatic artery embolization for treatment of benign hyperplasia. AJR Am J Roentgenol. 2014;203:813-821.

89. Gao YA, Huang Y, Zhang R, et al. Benign prostatic hyperplasia: prostatic arterial embolization versus transurethral resection of the prostate a prospective, randomized, and controlled clinical trial. Radiology. 2014;270:920-928.

90. Cano FG. Intraprostatic injection of antiseptic substances. Arch Rosales Hosp. 1910

91. Talwar G, Pande S. Injection treatment of enlarged prostate. Br J Surg. 1966;53:421-427.

92. Saemi AM, Plante MK. Injectables in the prostate. Curr Opin Urol. 2008; 18:28-33.

93. Larson BT, Netto N, Huidobro C, et al. Intraprostatic injection of alcohol gel for the treatment of benign prostatic hyperplasia: preliminary clinical results. ScientificWorldJournal. 2006;6:2474-2480.

94. Plante MK, Marks LS, Anderson R, et al. Phase I/II examination of transurethral ethanol ablation of the prostate for the treatment of symptomatic benign prostatic hyperplasia. J Urol. 2007;177:1030-1035.

95. Goya N, Ishikawa N, Ito F, Kobayashi C, Tomizawa Y, Toma H. Transurethral ethanol injection therapy for prostatic hyperplasia: 3-year results. J Urol. 2004;172:1017-1020.

96. Marberger M, Chartier-Kastler E, Egerdie B, et al. A randomized double-blind placebo-controlled phase 2 dose-ranging study of onabotulinumtoxinA in men with benign prostatic hyperplasia. Eur Urol. 2013;63:496-503.

97. Shore N. NX-1207: a novel investigational drug for the treatment of benign prostatic hyperplasia. Expert Opin Investig Drugs. 2010;19:305-310.

98. Denmeade SR, Egerdie B, Steinhoff G, Merchant R, Abi-Habib R, Pommerville P. Phase 1 and 2 studies demonstrate the safety and efficacy of intraprostatic injection of PRX302 for the targeted treatment of lower urinary tract symptoms secondary to benign prostatic hyperplasia. Eur Urol. 2011;59:747-754

99. Elhilali M, Pommerville P, Yocum RC, Merchant R, Roehrborn CG, Denmeade SR. Prospective, randomized, double-blind, vehicle controlled, multicenter Phase IIb clinical trial of the pore forming protein PRX302 for targeted treatment of symptomatic benign prostatic hyperplasia. J Urol. 2013;189:1421-1426.
Research and Reports in Urology

\section{Publish your work in this journal}

Research and Reports in Urology is an international, peer-reviewed, open access journal publishing original research, reports, editorials, reviews and commentaries on all aspects of adult and pediatric urology in the clinic and laboratory including the following topics: Pathology, pathophysiology of urological disease; Investigation and treatment of

\section{Dovepress}

urological disease; Pharmacology of drugs used for the treatment of urological disease. The manuscript management system is completely online and includes a very quick and fair peer-review system, which is all easy to use. Visit http://www.dovepress.com/testimonials.php to read real quotes from published authors. 